\title{
Use of the Airo mobile intraoperative CT system versus the O-arm for transpedicular screw fixation in the thoracic and lumbar spine: a retrospective cohort study of 263 patients
}

\author{
Pietro Scarone, MD, ${ }^{1}$ Gabriele Vincenzo, MD, ${ }^{2}$ Daniela Distefano, MD, ${ }^{2}$ Filippo Del Grande, MD, ${ }^{2}$ \\ Alessandro Cianfoni, MD, ${ }^{2}$ Stefano Presilla, $\mathrm{PhD},{ }^{3}$ and Michael Reinert, MD, PhD ${ }^{1}$
}

${ }^{1}$ Neurosurgical Service, Neurocenter of Southern Switzerland, and ${ }^{2}$ Radiology Department, Ospedale Regionale di Lugano; and ${ }^{3}$ Medical Physics Service, Ente Ospedaliero Cantonale, Bellinzona, Switzerland

OBJECTIVE Navigation-enabling technology such as 3D-platform (O-arm) or intraoperative mobile CT (iCT-Airo) systems for use in spinal surgery has considerably improved accuracy over that of traditional fluoroscopy-guided techniques during pedicular screw positioning. In this study, the authors compared 2 intraoperative imaging systems with navigation, available in their neurosurgical unit, in terms of the accuracy they provided for transpedicular screw fixation in the thoracic and lumbar spine.

METHODS The authors performed a retrospective analysis of clinical and surgical data of 263 consecutive patients who underwent thoracic and lumbar spine screw placement in the same center. Data on 97 patients who underwent surgery with iCT-Airo navigation (iCT-Airo group) and 166 with 0 -arm navigation (O-arm group) were analyzed. Most patients underwent surgery for a degenerative or traumatic condition that involved thoracic and lumbar pedicle screw fixation using an open or percutaneous technique. The primary endpoint was the proportion of patients with at least 1 screw not correctly positioned according to the last intraoperative image. Secondary endpoints were the proportion of screws that were repositioned during surgery, the proportion of patients with a postoperative complication related to screw malposition, surgical time, and radiation exposure. A blinded radiologist graded screw positions in the last intraoperative image according to the Heary classification (grade 1-3 screws were considered correctly placed).

RESULTS A total of 1361 screws placed in 97 patients in the iCT-Airo group (503 screws) and in 166 in the 0-arm group (858 screws) were graded. Of those screws, $3(0.6 \%)$ in the iCT-Airo group and $4(0.5 \%)$ in the 0-arm group were misplaced. No statistically significant difference in final accuracy between these 2 groups or in the subpopulation of patients who underwent percutaneous surgery was found. Three patients in the iCT-Airo group $(3.1 \%, 95 \% \mathrm{Cl} 0 \%-6.9 \%)$ and 3 in the 0 -arm group $(1.8 \%, 95 \% \mathrm{Cl} 0 \%-4.0 \%$ ) had a misplaced screw (Heary grade 4 or 5$)$. Seven (1.4\%) screws in the iCT-Airo group and $37(4.3 \%)$ in the 0 -arm group were repositioned intraoperatively $(p=0.003)$. One patient in the iCT-Airo group and 2 in the 0 -arm group experienced postoperative neurological deficits related to hardware malposition. The mean surgical times in both groups were similar (276 [iCT-Airo] and 279 [0-arm] minutes). The mean exposure to radiation in the iCT-Airo group was significantly lower than that in the O-arm group (15.82 vs $19.12 \mathrm{mSv}$, respectively; $p=0.02)$.

CONCLUSIONS Introduction of a mobile CT scanner reduced the rate of screw repositioning, which enhanced patient safety and diminished radiation exposure for patients, but it did not improve overall accuracy compared to that of a mobile 3D platform.

https://thejns.org/doi/abs/10.3171/2018.1.SPINE17927

KEYWORDS 3D imaging; computed tomography; intraoperative; navigation; pedicle screw; spine; lumbar; thoracic; surgical technique 
$\mathrm{U}$ SE of intraoperative navigation-enabling technologies in spinal surgery has improved the accuracy of pedicular screw positioning over that of freehand or fluoroscopy-guided methods..$^{12,14,25,29,30}$ Real-time fluoroscopic 3D imaging in the thoracic and lumbar spine ${ }^{24,25,27,31,38}$ resolves the variation in patient positioning before and during surgery, which can affect accuracy during surgical maneuvers. ${ }^{1,9,12}$ However, concerns about the accuracy of fluoroscopic 3D-imaging navigation during percutaneous screw positioning exist. ${ }^{27}$

A significant evolution of intraoperative real-time imaging was the introduction of a mobile $3 \mathrm{D}$ platform $(\mathrm{O}$ arm, Medtronic), ${ }^{2,4,13,17,26}$ which enables the acquisition of high-quality images with the surgical team outside of the room. This system provides information on pedicle anatomy, bony structures, and position of the screw(s). Radiation exposure can be reduced. ${ }^{17,19}$ Screw positioning with the aid of the $\mathrm{O}$-arm has been found to be more accurate than using fluoroscopy or a free-hand technique., ${ }^{11,31}$ It allows for 3D spine imaging in a limited field (maximum 4 lumbar vertebrae) with the cone-beam CT modality.

One intraoperative mobile CT (iCT) system for use in spinal surgery, ${ }^{8,16}$ the Airo CT scanner (Brainlab AG), was developed to be mobilized by a single operator. The scanner is linked to a carbon-fiber CT table (TruSystem 7500, Trumpf, Inc.) and an image-guidance system with an infrared tracking camera (Curve, Brainlab AG). An initial scan automatically transferred to the image-guidance system enables immediate use of CT navigation. Subsequent scans can be obtained after instrumentation positioning or lesion removal or to determine the extent of surgical decompression. This system enables a surgical team to obtain CT images of a patient in surgical position, without compulsory intraoperative surface matching, and acquire a single scan during extended posterior instrumentations, a function that is unavailable with other 3D-imaging systems. This system can increase surgical accuracy ${ }^{16}$ because its images are of longer portions of the spine and surrounding bony structures and of better quality than those with traditional CT. Experience in daily practice is needed to clarify its effect on surgical time during routine spinal surgery and on radiation exposure for the patient, because dose limits apply in planned-exposure situations for surgeons only, not for patients. ${ }^{36}$

In this retrospective cohort study, we compared the accuracy of screw positioning at the thoracic and lumbar levels during both open and percutaneous surgeries using iCT-Airo or O-arm technology.

Our primary objective was to compare the in vivo accuracy of these 2 navigation-enabling technologies during pedicular screw positioning at the thoracic and lumbar levels during percutaneous and open surgeries. Determining the rate of intraoperative screw repositioning, postoperative clinical results, surgical time, and radiation exposure were secondary objectives.

\section{Methods \\ Study Population}

The local ethics committee approved the reuse of clinical data for this study.
We reviewed the records of the Spine Operation Registry of the Neurosurgical Service at the Neurocenter of Southern Switzerland for patients who underwent posterior instrumented fusion with the use of navigation-enabling technology (O-arm or iCT-Airo) between January 2013 and November 2015. All the patients underwent urgent or elective surgery for a traumatic, degenerative, or neoplastic condition by a team of 6 surgeons with $>2$ years experience in navigated spinal surgery. Since October 2014, iCT-Airo navigation has been used in our hospital for all planned surgeries, and the O-arm was used only in the absence of a radiology technician.

Patients who were undergoing nonrevision surgery and had at least 4 pedicular screws positioned with navigation and had at least 2 documented intraoperative image sets were included. Patient demographics, admitting diagnosis, surgical technique, surgical level(s), and number of instrumented levels were recorded.

We compared patients who underwent surgery for screw implantation aided by $\mathrm{O}$-arm imaging coupled with the StealthStation navigation system (Medtronic) (O-arm group) with those who underwent surgery aided by iCTAiro imaging coupled with the Curve navigation system (Brainlab AG).

\section{Surgical Techniques}

O-arm Navigation

For open procedures, a reference clamp was attached to one of the spinous processes in the area of arthrodesis. For percutaneous surgery, the clamp was positioned according to surgeon preference; it was usually screwed to the iliac crest using a special clamp (Medtronic). For screws to be positioned in the thoracic spine from T1 to T6, the clamp was attached to a spinous process under the surgical field from $\mathrm{T} 7$ to T12. After clamp positioning, the O-arm was brought into the field for imaging in enhanced-3D mode (high definition). All personnel exited the room during image acquisition. Images were transferred to the navigation workstation, and the accuracy of registration was confirmed by verifying bony landmarks or, in percutaneous procedures, superficial landmarks on the skin and position of the line of the spinous processes.

For open procedures, after the entry point was identified by the register pointer and prepared with a 4-mm burr, a navigated awl was tracked and inserted through the pedicle. The surgeon verified accuracy of the trajectory through the axial, sagittal, and coronal views displayed by the navigation system. After they were tapped, holes were checked with a ball-tipped probe, and screws were positioned using navigation without additional image guidance (CD Horizon Legacy Spinal System, Medtronic). Alternatively, a power drill with a $2.6-\mathrm{mm}$ drill bit was inserted through a navigated drill guide (Medtronic). The guidewires were placed before tapping and screw positioning. Screw size was determined based on anatomical information received from the navigation system. Screws were sometimes inserted by aiming at a trajectory completely inside the cortical walls of the pedicle. An in-out-in technique ${ }^{25}$ was sometimes used as a salvage procedure only for very small thoracic pedicles. A confirmation scan 

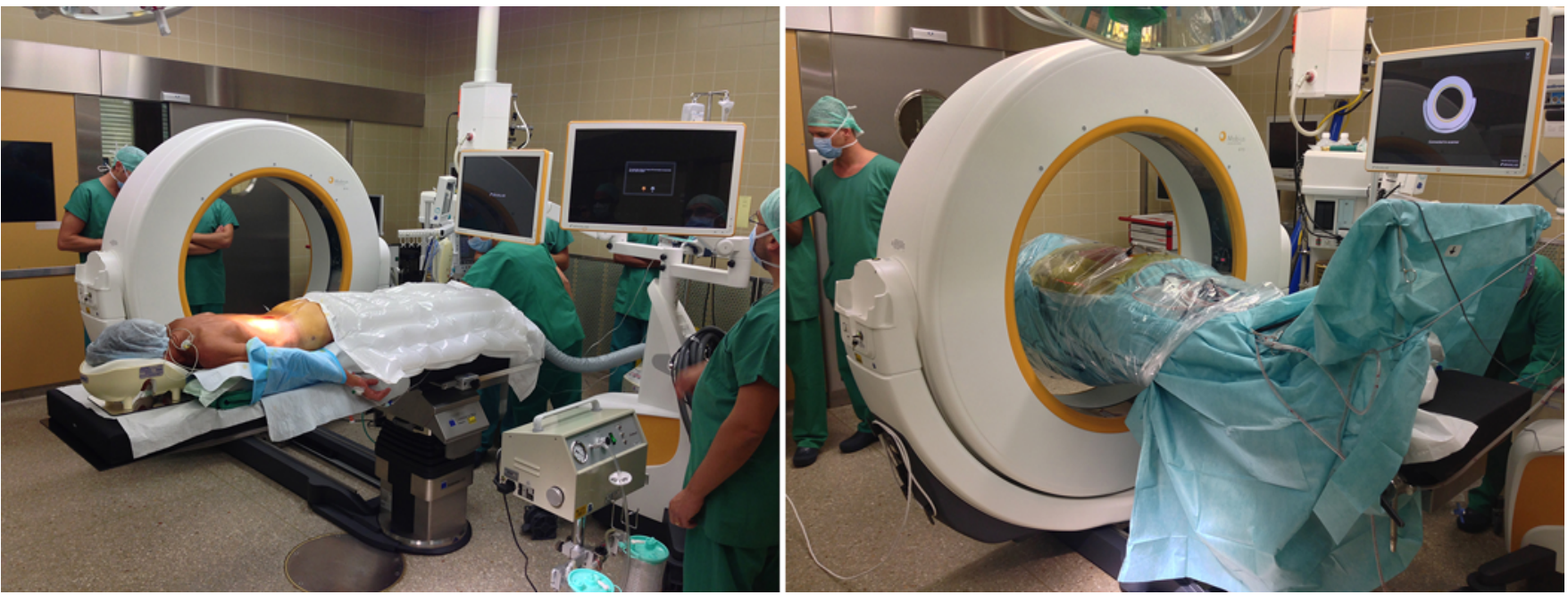

FIG. 1. Left: Intraoperative images from a lumbar procedure aided by iCT-Airo navigation. The patient is positioned prone on a mobile radiolucent carbon-fiber table (TruSystem 7500, Trumpf, Inc.) fixed to the gantry. Right: Every time a scan is needed, the surgical field is covered with a sterile drape, and the table is rotated toward the gantry. Figure is available in color online only.

was acquired immediately after placement of all pedicle screws to assess for acceptable screw positions (with a mediolateral cortical breach of $\leq 2 \mathrm{~mm}$ ). ${ }^{20,21}$ Those with a $>$ 2-mm mediolateral cortical breach or anterior violation at a thoracic level were repositioned, whereas the correction of anterior or lateral perforation of lumbar vertebral bodies was performed at the surgeon's discretion. The position of each replaced screw was verified by $\mathrm{O}$-arm scanning. After the insertion of all screws, decompression was performed and necessary interbody cages were inserted at the lumbar level, often through a transforaminal route. Cage position was controlled during insertion and at completion using the $\mathrm{O}$-arm in fluoroscopic modality.

For percutaneous procedures, a navigated pedicle-access kit with a disposable Jamshidi needle was used to enter the pedicle through a $1.5-\mathrm{cm}$ skin incision. From the entry point, the needle was advanced initially by a hammer and then by hand. A K-wire was then inserted and left in place for each trajectory. Screws were fixed on the wires only after they all were positioned and the surgeon judged their position on the confirmation scan to be correct. The surgeon replaced wires with a cortical breach of $>2 \mathrm{~mm}$. Screw size was determined in the same way as that for open procedures. A final fluoroscopic image was obtained after rod positioning.

\section{iCT-Airo Navigation}

A reference clamp was positioned as described for Oarm navigation. Each patient was placed in a prone position on a mobile radiolucent carbon-fiber table (TruSystem 7500, Trumpf, Inc.) fixed to the gantry, which enabled headfirst entry into the iCT gantry. The table was rotated manually to the gantry for each scan acquisition (Fig. 1), and a radiology technician executed the CT scans with a mobile CT scanner. ${ }^{8}$ Images were transferred automatically to our DICOM system and the navigation workstation. Afterward, the patient was rotated $90^{\circ}$ counterclockwise, and accuracy of the registration was confirmed.
For open procedures, the integrated Viper 2/Expedium system instruments with precalibrated cannulated and noncannulated awls, probes, and taps (DePuy Synthes) were used. After the entry point was identified by the register pointer and prepared with a 4-mm burr, a navigated pedicle finder of the appropriate size was tracked and inserted through the pedicle, which enabled the surgeon to check the accuracy of the trajectory through the axial, sagittal, and coronal views displayed by the navigation system. After they were tapped, the holes were checked with a ball-tipped probe, and screws were positioned using navigation without additional image guidance. Alternatively, a power drill with a 2.6-mm drill bit (Brainlab) was inserted through a navigated drill guide (Brainlab), and the guidewires were placed before tapping and screw positioning. Screw-size determination and assessments of screw accuracy and any need for replacement were performed the same way as that described for the O-arm.

For percutaneous procedures, a special navigated pedicle-access needle (Brainlab) was used, and screws were inserted as described for O-arm navigation.

\section{Evaluation of Screw Position Accuracy}

The images from the O-arm or iCT-Airo (axial cuts with coronal and sagittal reconstructions) obtained at the end of screw positioning (available in our hospital picture archiving and communications system) were used in this study by the radiologist to judge screw positions as correct. When artifacts in O-arm images were seen, CT images acquired after surgery were consulted to clarify screw position and possible encroachments of the pedicle cortex. We searched for any kind of postoperative motor or sensory neurological deficit and any vascular complication that involved thoracolumbar vessels clearly related to screw malposition or to an incorrect trajectory of the instruments (Jamshidi needles or Kirschner wires).

A radiologist blinded to the surgical technique graded screw placement according to the Heary classification ${ }^{7}$ 

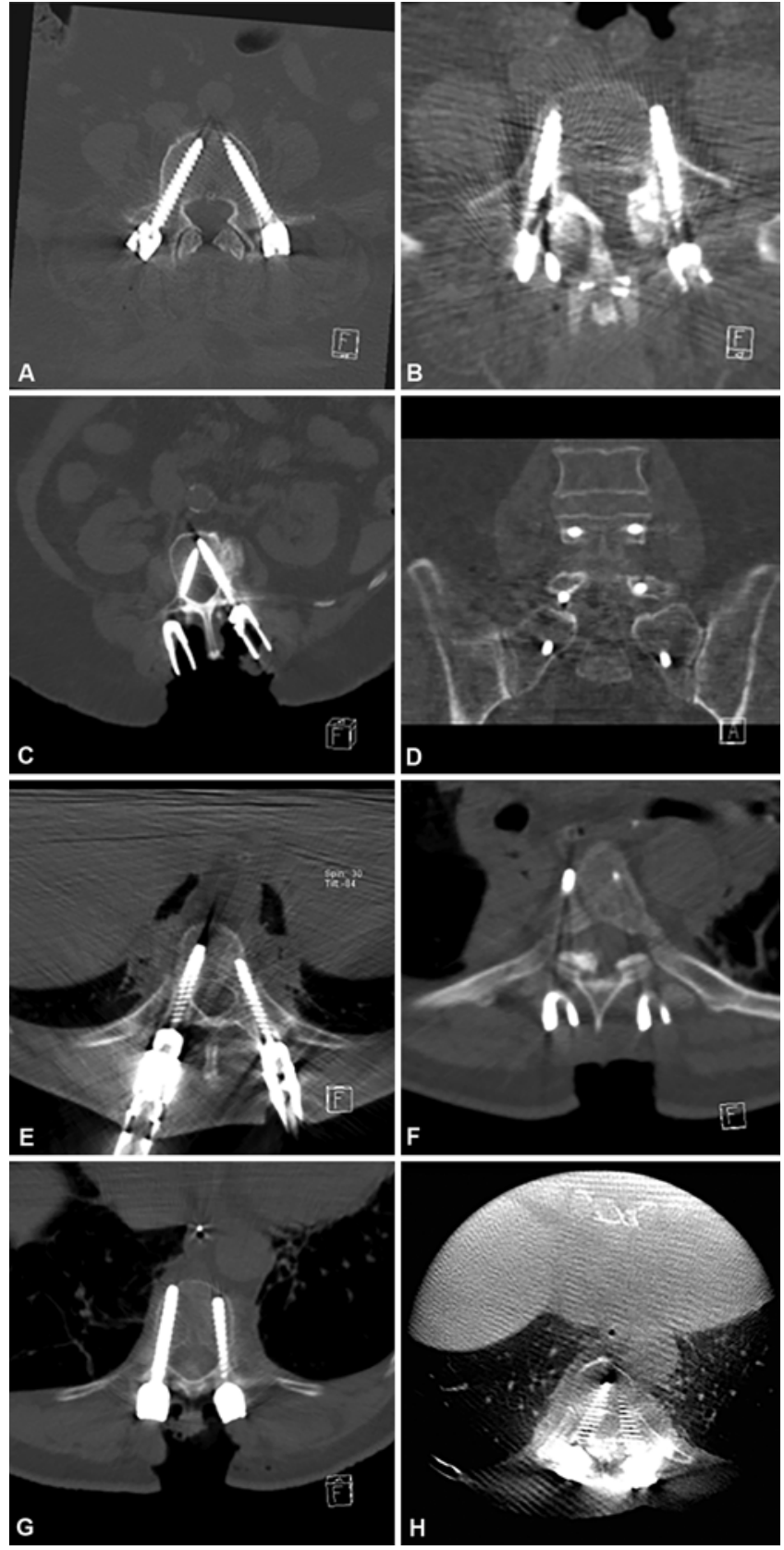

FIG. 2. Screws as seen with axial iCT images (A-D, lumbar; E-H, thoracic). A: Heary grade 2 screw (left). The lateral cortex of the pedicle is interrupted, but the tip of the screw is contained fully within the vertebral body. B: Heary grade 3 screw (left). The lateral cortical of the pedicle is interrupted, and the tip of the screw is outside the vertebral body. C: Heary grade 4 screw (right) that breaches the medial pedicle border. D: Heary grade 4 screw (right $L 5$ pedicle) that breaches the inferior pedicle border. E: Heary grade 2 screw (left) placed with a percutaneous technique (iCT-Airo). The screw violates the lateral pedicle wall but still is contained fully within the vertebral body. F: Heary grade 3 screw (right) (iCT-Airo). The screw violates the lateral pedicle wall, and the screw tip that has a triangular shape is outside the vertebral body that has a triangular shape. G: Heary grade 3 screw (right) (iCT-Airo). The breach of the lateral pedicle wall is not evident, but the tip of the screw is slightly outside the vertebral body $(<5 \mathrm{~mm})$. This screw was not intraoperatively repositioned. FIG. 2. (continued) $\rightarrow$
FIG. 2. H: With the O-arm, because of artifacts and lower-quality images, judging the position of the screw can be difficult, especially in patients with difficult anatomy and small pedicles, like this one. The screw on the right breaches the medial pedicle border and was given a Heary grade of 4 in this analysis. The surgeon decided not to replace the screw. The patient had a normal postoperative course with no new neurological symptoms.

(Fig. 2). This qualitative grading system allows for classification of screw position in relation to the pedicle wall and to the anterior and lateral cortexes of the vertebral body:6,15,20,21 grade 1, well-placed screw entirely contained within the pedicle and vertebral body; grade 2 , screw violates the lateral pedicle wall but is still within the pedicle-rib complex (at thoracic levels) and/or the tip of the screw is entirely within the vertebral body; grade 3 , screw tip penetrates the anterior vertebral body; grade 4, screw breaches the medial or inferior pedicle borders; and grade 5 , lateral or medial screw entirely out of the pedicle, endangers the spinal cord, nerve root, or great vessels, and requires immediate removal.

In this study, grade 1-3 screws were considered correctly placed, and grade 4 and 5 screws were considered misplaced. Screws placed in a very small thoracic pedicle using the in-out-in technique ${ }^{25}$ were classified as grade 2 .

The Heary system enables a precise and reliable evaluation of screw placement and has clear qualitative differences between each grade, including anterior vertebral body perforations potentially related to vascular complications at thoracic levels. ${ }^{35}$ The Heary method has advantages over quantitative methods, ${ }^{6,12}$ resulting in less intraobserver variability. Moreover, quantitative methods possibly underestimate screw malposition because of metallic artifacts around screws, ${ }^{1}$ and lack correlation with postoperative clinical symptoms. ${ }^{12}$

\section{Surgical Time}

Surgical time was computed as the number of minutes from the first surgical incision to skin closure.

\section{Quantification of Radiation Exposure}

Radiation exposure was recorded in milligrays per centimeters $(\mathrm{mGy} \cdot \mathrm{cm})$ (dose length product) for each procedure and navigation technique and converted to the effective dose, $\mathrm{E}$ (in millisieverts $[\mathrm{mSv}]$ ). ${ }^{36}$ The total effective dose was estimated by applying previously described conversion factors. ${ }^{3}$ The adopted conversion factors were $0.0145 \mathrm{mSv} \cdot \mathrm{mGy}^{-1} \cdot \mathrm{cm}^{-1}$ for thoracic and 0.0153 $\mathrm{mSv} \cdot \mathrm{mGy}^{-1} \cdot \mathrm{cm}^{-1}$ for lumbar surgeries; ${ }^{3} 120 \mathrm{kV}$ and adult age were the reference settings. These values concur with those of the American Association of Physicists in Medicine Report $96^{18}$ and others reported recently. ${ }^{19}$ We applied a full-dose protocol for the highest image quality in both groups. We routinely chose the high-definition 3D mode for the O-arm and, in most cases, "large" or "extra large" for patient size. A protocol with $100 \%$ of the dose was applied for patients in the iCT-Airo group.

\section{Outcome Measures}

The primary endpoint was the proportion of patients with at least 1 screw not positioned correctly. 
TABLE 1. Demographic and diagnostic characteristics

\begin{tabular}{|c|c|c|c|c|}
\hline Parameter & iCT-Airo Group & O-arm Group & Total & p Value \\
\hline Patients who underwent percutaneous or open surgery (no. [\%]) & $97(100)$ & $166(100)$ & $263(100)$ & \\
\hline $\operatorname{Sex}($ no. $[\%])$ & & & & $0.4^{*}$ \\
\hline Male & $45(46.4)$ & $68(41.0)$ & 113 & \\
\hline Female & $52(53.6)$ & $98(59.0)$ & 150 & \\
\hline \multicolumn{5}{|l|}{ Age in yrs } \\
\hline Mean (SD) & $63.0(14.7)$ & $64.7(14.3)$ & & $0.3 \dagger$ \\
\hline Median (IQR) & $67(22)$ & $68(16)$ & & $0.4 \ddagger$ \\
\hline Range & $18-86$ & $17-86$ & $17-86$ & \\
\hline Surgery type (no. [\%]) & & & & $0.1^{*}$ \\
\hline Open & $75(77.3)$ & $140(84.3)$ & 215 & \\
\hline Percutaneous & $22(22.7)$ & $26(15.7)$ & 48 & \\
\hline Diagnosis (no. [\%]) & & & & $0.2^{*}$ \\
\hline Degenerative & $78(80.4)$ & $122(73.5)$ & 200 & \\
\hline Neoplasia/trauma & $19(19.6)$ & $44(26.5)$ & 63 & \\
\hline$\geq 1$ thoracic screw placed (no. $[\%]$ ) & $20(20.6)$ & $36(21.7)$ & 56 & $0.8^{*}$ \\
\hline$\geq 1$ lumbar screw placed (no. [\%]) & $89(91.8)$ & $152(91.6)$ & & $0.9^{*}$ \\
\hline Interbody cage positioning (no. [\%]) & $70(72)$ & $97(58)$ & 167 & $0.02^{*}$ \\
\hline Mean no. of instrumented levels & 2.1 & 2.3 & 4.4 & $0.5 \dagger$ \\
\hline Patients who underwent percutaneous surgery (no. [\%]) & $22(100)$ & $26(100)$ & 48 & \\
\hline $\operatorname{Sex}($ no. $[\%])$ & & & & $0.9^{*}$ \\
\hline Male & $15(68.2)$ & $18(69.2)$ & 33 & \\
\hline Female & $7(31.8)$ & $8(30.8)$ & 15 & \\
\hline Age in yrs (median [IQR]) & $59.5(30)$ & $67(24)$ & & $0.9 \ddagger$ \\
\hline Preoperative diagnosis (no. [\%]) & & & & $<0.001^{*}$ \\
\hline Degenerative condition & $17(77.3)$ & $3(11.5)$ & 20 & \\
\hline Neoplasia/trauma & $5(22.7)$ & $23(88.5)$ & 28 & \\
\hline$\geq 1$ thoracic screw placed (no. [\%]) & $5(22.7)$ & $20(76.9)$ & 25 & $<0.001^{*}$ \\
\hline$\geq 1$ lumbar screw placed (no. [\%]) & $22(100)$ & $18(69.2)$ & 40 & $0.05 \S$ \\
\hline
\end{tabular}

The secondary endpoints were the number of intraoperatively repositioned screws on the first intraoperative image acquired after screw positioning, the proportion of patients with a postoperative neurological deficit and/or a vascular complication related to screw malposition based on intraoperative records and the patients' postoperative charts, surgical time, and radiation exposure (effective dose [E] to the patient).

\section{Statistical Analysis}

We created dichotomous variables for the screw outcomes (Heary grade 1,2, or 3, correctly positioned screw; Heary grade 4 or 5 , misplaced screw). Proportions are given with the $95 \%$ confidence interval $(95 \% \mathrm{CI})$, means with standard deviation $( \pm \mathrm{SD})$, and medians with interquartile ranges (IQRs). The association between categorical variables was investigated by the chi-square test and the Fisher exact test when expected frequencies were $<5$. The Student t-test or the Mann-Whitney U-test was used for continuous variables. Patient age, surgical time, and radiation exposure were square-root transformed. All tests were 2-tailed, and significance was set at $p<0.05$. All statistical analyses were performed using SPSS 21.0 for Windows (IBM).

\section{Results \\ Patient Cohorts}

Data of 97 patients who underwent surgery aided by iCT-Airo navigation and 166 who underwent surgery aided by $\mathrm{O}$-arm navigation were available for analysis. The 2 groups were comparable in their demographic and diagnostic characteristics except for interbody cage positioning (70 [72\%] in the iCT-Airo group and 97 [58\%] in the $\mathrm{O}$-arm group; $\mathrm{p}=0.02$, chi-square test). Most patients underwent surgery for a degenerative condition (spinal stenosis, spondylolisthesis, or instability); none did so for idiopathic scoliosis or major deformity. Most surgeries involved lumbar pedicle screw positioning for single- or double-level degenerative disease. The mean number of 
TABLE 2. Screws at each grading category according to surgical and navigation technique

\begin{tabular}{|c|c|c|c|c|c|c|c|}
\hline \multirow{2}{*}{$\begin{array}{c}\text { Surgical \& Navigation } \\
\text { Technique }\end{array}$} & \multirow{2}{*}{$\begin{array}{l}\text { Surgical } \\
\text { Level }\end{array}$} & \multicolumn{5}{|c|}{ No. of Screws Positioned According to Heary Grade* } & \multirow[b]{2}{*}{ Total } \\
\hline & & Grade 1 & Grade 2 & Grade 3 & Grade 4 & Grade 5 & \\
\hline Percutaneous \& open surgery & & $1,253(92.1)$ & $27(2.0)$ & $74(5.4)$ & $7(0.5)$ & $0(0.0)$ & $1,361(100)$ \\
\hline \multirow[t]{2}{*}{ iCT-Airo } & Thoracic & $116(95.1)$ & $3(2.5)$ & $3(2.5)$ & $0(0.0)$ & $0(0.0)$ & $122(100)$ \\
\hline & Lumbar & $346(91.0)$ & $5(1.3)$ & $27(7.1)$ & $3(0.8)$ & $0(0.0)$ & $381(100)$ \\
\hline \multirow[t]{2}{*}{ O-arm } & Thoracic & $189(88.7)$ & $14(6.6)$ & $8(3.8)$ & $2(1.0)$ & $0(0.0)$ & $213(100)$ \\
\hline & Lumbar & $602(93.3)$ & $5(0.8)$ & $36(5.6)$ & $2(0.3)$ & $0(0.0)$ & $645(100)$ \\
\hline Open surgery & & $979(91.6)$ & $16(1.5)$ & $70(6.5)$ & $4(0.4)$ & $0(0.0)$ & $1,069(100)$ \\
\hline iCT-Airo & & $365(91.0)$ & $4(1.0)$ & $29(7.2)$ & $3(0.7)$ & $0(0.0)$ & $401(100)$ \\
\hline O-arm & & $614(91.9)$ & $12(1.8)$ & $41(6.1)$ & $1(0.1)$ & $0(0.0)$ & $668(100)$ \\
\hline Percutaneous surgery & & $274(93.8)$ & $11(3.8)$ & $4(1.4)$ & $3(1.0)$ & $0(0.0)$ & $292(100)$ \\
\hline \multirow[t]{3}{*}{ iCT-Airo } & & 97 (95.1) & $4(3.9)$ & $1(1.0)$ & $0(0.0)$ & $0(0.0)$ & $102(100)$ \\
\hline & Thoracic & $21(95.5)$ & $1(4.5)$ & $0(0.0)$ & $0(0.0)$ & $0(0.0)$ & $22(100)$ \\
\hline & Lumbar & $76(95.0)$ & $3(3.8)$ & $1(1.3)$ & $0(0.0)$ & $0(0.0)$ & $80(100)$ \\
\hline \multirow[t]{3}{*}{ O-arm } & & $177(93.2)$ & $7(3.7)$ & $3(1.6)$ & $3(1.6)$ & $0(0.0)$ & $190(100)$ \\
\hline & Thoracic & $106(90.6)$ & $7(6.0)$ & $3(2.6)$ & $1(0.9)$ & $0(0.0)$ & $117(100)$ \\
\hline & Lumbar & $71(97.3)$ & $0(0.0)$ & $0(0.0)$ & $2(2.7)$ & $0(0.0)$ & $73(100)$ \\
\hline
\end{tabular}

Values are presented as the number (\%) of screws.

* Percentages may not add up to $100 \%$ because of rounding.

TABLE 3. Accuracy of screw positions

\begin{tabular}{|c|c|c|c|}
\hline $\begin{array}{c}\text { Surgical Level \& } \\
\text { Navigation Technique }\end{array}$ & $\begin{array}{c}\text { No. of } \\
\text { Correctly } \\
\text { Placed } \\
\text { Screws, } \\
\text { Heary Grades } \\
\text { 1-3 }\end{array}$ & $\begin{array}{l}\text { No. of } \\
\text { Misplaced } \\
\text { Screws, } \\
\text { Heary } \\
\text { Grades } \\
4 \text { and } 5\end{array}$ & $\begin{array}{l}\text { Total } \\
\text { (no.) }\end{array}$ \\
\hline Percutaneous \& open surgery* & $1,354(99.5)$ & $7(0.5)$ & 1,361 \\
\hline iCT-Airo & $500(99.4)$ & $3(0.6)$ & 503 \\
\hline O-arm & $854(99.5)$ & $4(0.5)$ & 858 \\
\hline Thoracic & $333(99.4)$ & $2(0.6)$ & 335 \\
\hline iCT-Airo & $122(100)$ & $0(0.0)$ & 122 \\
\hline O-arm & $211(99.1)$ & $2(0.9)$ & 213 \\
\hline Lumbar & $1,021(99.5)$ & $5(0.5)$ & 1,026 \\
\hline iCT-Airo & $378(99.2)$ & $3(0.8)$ & 381 \\
\hline O-arm & $643(99.7)$ & $2(0.3)$ & 645 \\
\hline Percutaneous surgery† & $289(99.0)$ & $3(1.0)$ & 292 \\
\hline iCT-Airo & $102(100)$ & $0(0.0)$ & 102 \\
\hline O-arm & $187(98.4)$ & $3(1.6)$ & 190 \\
\hline Thoracic & 138 (99.3) & $1(0.7)$ & 139 \\
\hline iCT-Airo & $22(100)$ & $0(0.0)$ & 22 \\
\hline O-arm & $116(99.1)$ & $1(0.9)$ & 117 \\
\hline Lumbar & $151(98.7)$ & $2(1.3)$ & 153 \\
\hline iCT-Airo & $80(100)$ & $0(0.0)$ & 80 \\
\hline O-arm & 71 (97.3) & $2(2.7)$ & 73 \\
\hline
\end{tabular}

Values are presented as the number (\%) of screws.

${ }^{*}$ Fisher exact test, $p=0.7$.

$\dagger$ Fisher exact test, $p=0.55$. instrumented levels was 2.1 in the iCT-Airo group and 2.3 in the $\mathrm{O}$-arm group $(\mathrm{p}=0.5$, t-test) (Table 1$)$.

Forty-eight patients (18\%), $22(23 \%)$ in the iCT-Airo group and $26(16 \%)$ in the O-arm group, had screws placed percutaneously. Preoperative diagnoses and numbers of patients with screws at the thoracic and lumbar levels were statistically significantly different between the 2 groups ( $p$ $<0.001$, chi-square test) (Table 1).

\section{Screw Accuracy \\ Overall}

A total of 1361 screws were graded. No screw was classified as grade 5 (Table 2).

Three $(0.6 \%)$ screws in the iCT-Airo group and 4 $(0.5 \%)$ in the $\mathrm{O}$-arm group were misplaced (Heary grade 4) ( $p=0.7$, Fisher exact test); $99.5 \%$ (99.4\% in the iCTAiro group, $99.5 \%$ in the $\mathrm{O}$-arm group) of the screws were Heary grade 1-3 (Table 3).

\section{Percutaneous Technique}

In total, 292 (21\%) screws were placed using a navigated percutaneous technique, 139 at thoracic levels and 153 at lumbar levels (Table 2); $99 \%$ of these screws were placed correctly. Three (1.5\%) screws in the O-arm group were misplaced (grade 4), and no screw in the iCT-Airo group was misplaced ( $p=0.55$, Fisher exact test) (Table 3 ).

\section{Primary Endpoint: Proportion of Patients With a Misplaced Screw}

Three $(3.1 \%, 95 \%$ CI $0 \%-6.9 \%)$ patients in the iCTAiro group and $3(1.8 \%, 95 \% \mathrm{CI} 0 \%-4.0 \%)$ in the O-arm group had a misplaced screw (Heary grade 4$)(p=0.7$, Fisher exact test). In the iCT-Airo group, the misplaced screws were positioned at a lumbar level, and in the O-arm 
TABLE 4. Proportion of patients with misplaced screws according to surgical technique, level, and navigation method (primary endpoint)

\begin{tabular}{|c|c|c|c|c|c|}
\hline \multirow[b]{2}{*}{ Surgical Technique } & \multicolumn{2}{|c|}{ iCT-Airo Group } & \multicolumn{2}{|c|}{ O-arm Group } & \multirow[b]{2}{*}{$\begin{array}{c}p \\
\text { Value* }\end{array}$} \\
\hline & $\begin{array}{l}\text { No. } \\
(\%)\end{array}$ & $\begin{array}{c}95 \% \\
\mathrm{Cl}\end{array}$ & $\begin{array}{l}\text { No. } \\
(\%)\end{array}$ & $\begin{array}{c}95 \% \\
\mathrm{Cl}\end{array}$ & \\
\hline Percutaneous \& open & $97(100)$ & & $166(100)$ & & \\
\hline Heary grades 4 \& 5 & $3(3.1)$ & $0-6.9$ & $3(1.8)$ & $0-4.0$ & 0.7 \\
\hline Thoracic & 0 & & 2 & & \\
\hline Lumbar & 3 & & 1 & & \\
\hline Percutaneous & $22(100)$ & & $26(100)$ & & \\
\hline Heary grades 4 \& 5 & $0(0.0)$ & $0-0$ & $2(7.7)$ & $0-19.2$ & 0.5 \\
\hline Thoracic & 0 & & 1 & & \\
\hline Lumbar & 0 & & 1 & & \\
\hline
\end{tabular}

* Fisher exact test.

group, 2 of 3 patients had them positioned at a thoracic level (Table 4).

The proportion of patients who underwent percutaneous surgery that resulted in at least 1 misplaced screw was higher in the O-arm group than in the iCT-Airo group $(7.7 \%$ vs $0 \%$, respectively; $p=0.5$, Fisher exact test) (Table 4).

\section{Secondary Endpoints}

Repositioned Screws

Seven $(1.4 \%)$ of 503 screws in the iCT-Airo group and $37(4.3 \%)$ of 858 screws in the O-arm group $(\mathrm{p}=0.003$, chi-square test) were repositioned intraoperatively. In the group of patients who underwent percutaneous surgery, $26.9 \%$ of patients in the $\mathrm{O}$-arm group and $4.5 \%$ in the iCTAiro group ( $\mathrm{p}=0.05$, Fisher exact test) underwent screw repositioning (Table 5).

\section{Patients With Postoperative Complications Related to Screw Malposition}

One patient in the iCT-Airo group who underwent open surgery and 2 patients in the $\mathrm{O}$-arm group who underwent percutaneous surgery presented with postoperative neurological deficits related to a malpositioned screw or trocar $(\mathrm{p}=0.8$, chi-square test) (Table 5).

In the iCT-Airo group, a 77-year-old woman experienced a partial motor deficit (M2) in her right foot after medial repositioning of an L5 pedicle screw in open surgery that needed a new intervention on postoperative day 1. The screw was classified as Heary grade 4 on the final intraoperative CT image that was acquired before repositioning. The new screw position was not verified by an intraoperative scan.

In the O-arm group, a 57-year-old patient with an L1 fracture after positioning of a Jamshidi needle to prepare the trajectory for a T11 right percutaneous screw suffered major bleeding, which was stopped using a hemostatic agent. Surgery was completed without screw positioning on the T11 pedicle. The patient experienced major perfusion problems in both limbs immediately after the procedure. A thoracic CT angiogram revealed a thrombus in the aorta, probably as a result of migration of the hemostatic
TABLE 5. Intraoperatively repositioned screws and neurological or vascular complications

\begin{tabular}{cccc}
\hline Surgical Technique & $\begin{array}{c}\text { iCT-Airo } \\
\text { Group }\end{array}$ & $\begin{array}{c}\text { O-arm } \\
\text { Group }\end{array}$ & $\begin{array}{c}\text { p } \\
\text { Value }\end{array}$ \\
\hline $\begin{array}{c}\text { Percutaneous \& open surgery } \\
\text { (no. of patients) }\end{array}$ & $97(100)$ & $166(100)$ & \\
\hline $\begin{array}{c}\text { Patients w/ neurological or } \\
\text { vascular complication }\end{array}$ & $1(1.0)$ & $2(1.2)$ & $0.8^{*}$ \\
\hline No. of screws positioned & $503(100)$ & $858(100)$ & \\
\hline No. of screws repositioned & $7(1.4)$ & $37(4.3)$ & $0.003 \dagger$ \\
\hline Percutaneous surgery & $22(100)$ & $26(100)$ & \\
\hline $\begin{array}{c}\text { Patients w/ neurological or } \\
\text { vascular complication }\end{array}$ & $0(0)$ & $2(7.7)$ & $0.5^{*}$ \\
\hline Patients w/ screw repositioning & $1(4.5)$ & $7(26.9)$ & $0.05 \ddagger$ \\
\hline Vation
\end{tabular}

Values are presented as the number (\%) of screws or patients.

* Chi-square test.

$\dagger$ Chi-square $=8.64$, degrees of freedom $=1$.

$\ddagger$ Fisher exact test.

agent in the segmental vessel at T11. A thoracotomy was performed, and the thrombus was removed, which resulted in complete clinical recovery. On the final CT scan, this patient's screws were all classified as Heary grade 1. This major complication was related to an accuracy error, because the needle positioning appeared to be correct on the screen, but the real position was lateral to the vertebral body. In the second case, a postoperative right foot drop (M2) developed after incorrect positioning of a Jamshidi needle at the right T11 level with CSF leakage after entrance in a 46-year-old woman treated for a T12 fracture with a posterior percutaneous fixation from T11 to L1. The Jamshidi needle was repositioned under O-arm fluoroscopic control. In the final CT scan, the T-11 screws in this patient were judged to be Heary grade 1 .

These inaccuracies of the navigation systems were probably caused by an intraoperative movement of the reference clamp, because it was either fixed improperly or hammered during disposable Jamshidi needle or pedicular probe positioning.

\section{Surgical Time}

The mean surgical times were similar in both groups (276.4 minutes [iCT-Airo group] and 278.8 minutes [Oarm group]) ( $\mathrm{p}=0.8, \mathrm{t}$-test). In the patients who underwent percutaneous surgery, surgical time trend-wise was longer in the iCT-Airo group than in the O-arm group (p $=0.3$, Wilcoxon-Mann-Whitney test) (Table 6 ). The team's familiarization with the iCT-Airo navigation technique improved significantly the surgical time for the last 57 patients over that of the first 40 patients (255.0 vs 306.8 minutes, respectively; $p=0.002$ ).

\section{Radiation Exposure}

The numbers of initial scans for navigation and intraoperative acquisitions were equal in both groups. The patients' exposure to radiation in the iCT-Airo group was statistically significantly lower than that in the O-arm group (15.82 vs $19.12 \mathrm{mSv}$, respectively; $\mathrm{p}=0.02$, t-test) (Table 6). 
TABLE 6. Surgical times and radiation exposure

\begin{tabular}{lccc}
\hline \multicolumn{1}{c}{ Variable } & $\begin{array}{c}\text { iCT-Airo } \\
\text { Group }\end{array}$ & $\begin{array}{c}\text { O-arm } \\
\text { Group }\end{array}$ & $\begin{array}{c}p \\
\text { Value }\end{array}$ \\
\hline Surgical time & & & \\
\hline $\begin{array}{l}\text { Percutaneous \& open surgery } \\
\text { (no.) }\end{array}$ & 97 & 166 & \\
\hline Mean surgical time in mins (SD) & $276.4(81.5)$ & $278.8(89.4)$ & $0.8^{*}$ \\
\hline Percutaneous surgery (no.) & 22 & 26 & \\
\hline $\begin{array}{l}\text { Median surgical time in mins } \\
\text { (IQR) }\end{array}$ & $232.5(76)$ & $214.5(98)$ & $0.3 \dagger$ \\
\hline Radiation exposure (no.) & 92 & 51 & \\
\hline$\quad$ mSv (SD) & $15.82(6.6)$ & $19.12(9.6)$ & $0.02^{*}$ \\
\hline CTDI transformed values (mGy) & 22.7 & 30.7 & \\
\hline $\begin{array}{l}\text { CTDI = CT dose index. } \\
\text { *t-test (after square-root transformation). } \\
\text { † Wilcoxon-Mann-Whitney test. }\end{array}$ & & & \\
\end{tabular}

\section{Discussion}

Our results, based on analysis of more than 1300 screws, confirm that the use of high-quality intraoperative navigation and 3D-imaging technology effectively reduces the rate of pedicle perforation by pedicular screws and diminishes the need for screw repositioning. In patients who underwent surgery performed via the navigated percutaneous technique, we achieved a very high accuracy rate with both navigation-enabling technologies (99\% correctly placed screws).

The 2 navigation-enabling technologies were equivalent regarding the numbers of misplaced screws and the proportions of patients with a misplaced screw; the rates of misplacement were low in both groups. The rate of misplaced screws, the proportion of patients with at least 1 misplaced screw, and the number of major vascular and neurological complications were higher in the O-arm group, but this result was not statistically significant. Misplaced screws penetrated the spinal canal medially. One screw was associated with a postoperative neurological complication in a patient in the iCT-Airo group and required surgical intervention. Other grade 4 screws were not identified during surgery because of imaging artifacts (O-arm) or were not repositioned mainly because of the patients' extremely narrow pedicles. Intraoperative neuromonitoring was not used during screw placement; its application might have enabled us to detect a signal abnormality during positioning and prompted trajectory correction. Heary grade 3 lumbar screws $(<3 \mathrm{~mm}$ over the anterior cortical wall) were not associated with postoperative vascular or neurological complications and not repositioned, which confirms recent results of biomechanical studies on bicortical lumbar screws..$^{10}$

The number of intraoperatively repositioned screws in the iCT-Airo (1.4\%) and O-arm (4.3\%) groups was significantly different. This result implies that, although the final accuracy rates were similar, initial breaches (based on navigation and $3 \mathrm{D}$-rescanning confirmations) were more common with the $\mathrm{O}$-arm. The rate of intraoperative repositioning of screws must be evaluated carefully, because it could be related directly to a lack of precision of the system used to navigate the screws. Moreover, using intraoperative CT to check for screw position prompts surgeons to revise screws more often than when conventional fluoroscopy is used, but the clinical effect of revision is unknown. Rates of intraoperative repositioning between $2.6 \%$ and $4 \%$ with conventional techniques and between $7.2 \%$ and $8.8 \%$ with iCT have been reported. ${ }^{1,14,31}$ Our revision rate of $1.4 \%$ with the iCT-Airo is lower than that obtained previously with a 40 -slice scanner ${ }^{1}$ and the $\mathrm{O}$ $\operatorname{arm}^{2}$ and can be explained by the higher intraoperative image quality and precise navigation system. The higher revision rate observed in the $\mathrm{O}$-arm group is explained by lower image quality in the thoracic spine and in osteoporotic cases.

Overall, our results call for an increased use of iCT navigation in association with less-invasive percutaneous pedicular fixation, because intraoperative imaging data and navigation allowed for optimal screw positioning in the vast majority of cases.

In fact, the accuracy shown in both groups in this study with the percutaneous technique was high (the rates of misplacement were $0 \%$ in the iCT-Airo group and $1.5 \%$ in the $\mathrm{O}$-arm group), even though a higher number of patients underwent intraoperative screw revision in the $\mathrm{O}$ arm group.

These data should be compared with reported perforation rates of $24 \%$ with fluoro-navigation and $5 \%$ with conventional fluoroscopic guidance. ${ }^{27}$ The high misplacement rate in this previous study was explained by the use of vertebroplasty trocars without enough rigidity used for K-wire positioning and low-quality intraoperative images caused by high body mass index of and osteoporosis in some patients, which confirms our experience with navigation-assisted percutaneous fixation. Indeed, we always used a rigid navigated pedicle-access needle with the iCTAiro and a less-rigid disposable Jamshidi needle with the $\mathrm{O}$-arm. The instrument used, not the imaging modality, was probably the main cause for the intraoperative revisions in our O-arm group; it should also be noted that significantly more screws in this group were placed in the thoracic spine. However, we often observed suboptimalquality images with the $\mathrm{O}$-arm at thoracic levels, especially in osteoporotic and obese patients.

Our results underline the importance of using intraoperative imaging and navigation systems of the highest quality when performing percutaneous fixation techniques on the thoracic spine.

\section{Screw Accuracy}

Our results agree with published data and show an accuracy rate higher than that of any other previously published study. The rates of misplaced screws were $0.6 \%$ in our iCT-Airo group and $0.5 \%$ in our O-arm group, and no severe breach occurred. In a randomized controlled study that included 100 patients, the pedicle perforation rate was $4.6 \%$ with navigation, and no screw had a pedicle perforation rate of $>4 \mathrm{~mm} .{ }^{14}$ In another retrospective study, the accuracy rates were $94.1 \%$ for free-hand navigation and $99 \%$ for $\mathrm{O}$-arm navigation, and 2 (1\%) screws placed with $\mathrm{O}$-arm navigation were misplaced and resulted in a penetration of 
$>3 \mathrm{~mm} ; 1$ of these penetrations was severe $(>6 \mathrm{~mm}) .{ }^{31} \mathrm{~A}$ meta-analysis of more than 8000 pedicle screws revealed a $6 \%$ risk of pedicle perforation with navigation-enabling techniques versus a $15 \%$ risk without navigation. ${ }^{29}$

Unlike intraoperative mobile CT imaging associated with navigation, conventional CT for pedicular screw positioning is well documented. ${ }^{32,33,37}$ A recent study on Airo CT-based navigation reported perforation rates of $6.8 \%$ for lumbar and $2.5 \%$ for thoracic screws and no misplaced screws $(>4 \mathrm{~mm})$ in a sample of 137 screws. $^{8}$

Few studies have compared different navigation methods for pedicular screw positioning. A literature review, which included studies that reported a quantitative method for screw accuracy evaluation (2-mm increments), 30\% of which used $\mathrm{O}$-arm navigation, found a higher mean accuracy rate for the StealthSystem (Medtronic) than for the VectorVision (Brainlab) navigation system (98.71\% vs $95.82 \%$, respectively). ${ }^{22}$

\section{Surgical Time}

The addition of intraoperative CT can increase surgical time by 25 to 50 minutes. ${ }^{1,8}$ Prolonged $^{14,28}$ and reduced ${ }^{13}$ surgical times with navigation technologies have been reported. A recent meta-analysis of 4 studies of navigation versus free-hand pedicle screw accuracy reported a mean surgical time of 135-443 minutes when navigation techniques were used. ${ }^{29}$ Our mean surgical time was approximately 270 minutes in both groups.

\section{Radiation Exposure}

Spinal navigation and computer-assisted spinal surgery can reduce radiation exposure for operating room staff significantly, ${ }^{5,23}$ but with the use of iCT, exposure could increase for patients.

Our use of an image-acquisition protocol optimized for the best image quality is the reason that the measured doses were significantly higher than those reported in the literature. ${ }^{23}$ In the absence of a specific diagnostic reference level (DRL) for pedicle screw positioning, the ALARA (as low as reasonably achievable) principle and the national DRL (nDRL) for lumbar spine radiological CT examination $^{34}$ were used to optimize exposure. Usual optimal radiation-exposure levels for lumbar spine CT acquisitions are 30 and 16 mGy. ${ }^{18}$ In our setting, each spin emitted a satisfactorily optimized dose exposure.

The mean radiation dose for patients in the iCT-Airo group was lower than that in the $\mathrm{O}$-arm group, contrary to the results of a study ${ }^{39}$ in which 1 acquisition by the Oarm equaled $47 \%-83 \%$ of the dose absorbed from a CT scanner.

The higher dose observed with the $\mathrm{O}$-arm resulted from the high-dose setting for the highest image quality and also its regular use in fluoroscopic mode during interbody cage positioning (placed in $62 \%$ of the 51 cases in the O-arm group analyzed for radiation dose) and to check final position of the rods during percutaneous surgeries, whereas in the iCT-Airo group, the effective dose resulted only from scout images and CT acquisitions.

Our study is limited by its retrospective nature, the relatively low number of thoracic screws placed percutaneously with iCT-Airo navigation, and the study population with few patients suffering from significant degenerative scoliosis, which confers a higher risk of inaccuracy and neurological complications. ${ }^{35}$

\section{Conclusions}

The introduction of mobile iCT scanning reduced the rate of screw repositioning, which enhanced patient safety and diminished radiation exposure for patients, but it did not improve overall accuracy compared to that with use of a mobile 3D platform.

\section{Acknowledgments}

We gratefully acknowledge the contribution by Paola GandolfiDecristophoris, $\mathrm{PhD}$, Cresciano, Switzerland, for the statistical analyses and Liliane Petrini, PhD, Neurocenter of Southern Switzerland, Ospedale Regionale di Lugano, for medical writing support.

\section{References}

1. Bydon M, Xu R, Amin AG, Macki M, Kaloostian P, Sciubba DM, et al: Safety and efficacy of pedicle screw placement using intraoperative computed tomography: consecutive series of 1148 pedicle screws. J Neurosurg Spine 21:320-328, 2014

2. Costa F, Cardia A, Ortolina A, Fabio G, Zerbi A, Fornari M: Spinal navigation: standard preoperative versus intraoperative computed tomography data set acquisition for computerguidance system: radiological and clinical study in 100 consecutive patients. Spine (Phila Pa 1976) 36:2094-2098, 2011

3. Deak PD, Smal Y, Kalender WA: Multisection CT protocols: sex- and age-specific conversion factors used to determine effective dose from dose-length product. Radiology 257:158166,2010

4. Epstein NE: Commentary: Utility of the O-arm in spinal surgery. Surg Neurol Int 5 (Suppl 15):S517-S519, 2014

5. Gebhard FT, Kraus MD, Schneider E, Liener UC, Kinzl L, Arand M: Does computer-assisted spine surgery reduce intraoperative radiation doses? Spine (Phila Pa 1976) 31:20242028, 2006

6. Gertzbein SD, Robbins SE: Accuracy of pedicular screw placement in vivo. Spine (Phila Pa 1976) 15:11-14, 1990

7. Heary RF, Bono CM, Black M: Thoracic pedicle screws: postoperative computerized tomography scanning assessment. J Neurosurg 100 (4 Suppl Spine):325-331, 2004

8. Hecht N, Kamphuis M, Czabanka M, Hamm B, König S, Woitzik J, et al: Accuracy and workflow of navigated spinal instrumentation with the mobile AIRO ${ }^{\circledR} \mathrm{CT}$ scanner. Eur Spine J 25:716-723, 2016

9. Holly LT: Image-guided spinal surgery. Int J Med Robot 2:7-15, 2006

10. Karami KJ, Buckenmeyer LE, Kiapour AM, Kelkar PS, Goel VK, Demetropoulos CK, et al: Biomechanical evaluation of the pedicle screw insertion depth effect on screw stability under cyclic loading and subsequent pullout. J Spinal Disord Tech 28:E133-E139, 2015

11. Kim TT, Drazin D, Shweikeh F, Pashman R, Johnson JP: Clinical and radiographic outcomes of minimally invasive percutaneous pedicle screw placement with intraoperative CT $(\mathrm{O}$-arm) image guidance navigation. Neurosurg Focus 36(3):E1, 2014

12. Kosmopoulos V, Schizas C: Pedicle screw placement accuracy: a meta-analysis. Spine (Phila Pa 1976) 32:E111-E120, 2007

13. Kotani T, Akazawa T, Sakuma T, Koyama K, Nemoto T, Nawata K, et al: Accuracy of pedicle screw placement in sco- 
liosis surgery: a comparison between conventional computed tomography-based and $\mathrm{O}$-arm-based navigation techniques. Asian Spine J 8:331-338, 2014

14. Laine T, Lund T, Ylikoski M, Lohikoski J, Schlenzka D: Accuracy of pedicle screw insertion with and without computer assistance: a randomised controlled clinical study in 100 consecutive patients. Eur Spine J 9:235-240, 2000

15. Learch TJ, Massie JB, Pathria MN, Ahlgren BA, Garfin SR: Assessment of pedicle screw placement utilizing conventional radiography and computed tomography: a proposed systematic approach to improve accuracy of interpretation. Spine (Phila Pa 1976) 29:767-773, 2004

16. Lee CY, Wu MH, Li YY, Cheng CC, Hsu CH, Huang TJ, et al: Intraoperative computed tomography navigation for transpedicular screw fixation to treat unstable thoracic and lumbar spine fractures: clinical analysis of a case series (CAREcompliant). Medicine (Baltimore) 94:e757, 2015

17. Mattei TA, Fassett DR: The O-arm revolution in spine surgery. J Neurosurg Spine 19:644-647, 2013 (Letter)

18. McCollough C, Cody D, Edyvean S, Geise R, Gould B, Keat $\mathrm{N}$, et al: The Measurement, Reporting, and Management of Radiation Dose in CT. College Park, MD: American Association of Physicists in Medicine, 2008, p 28 (https://www.aapm. org/pubs/reports/RPT_96.pdf ) [Accessed March 14, 2018]

19. Mendelsohn D, Strelzow J, Dea N, Ford NL, Batke J, Pennington A, et al: Patient and surgeon radiation exposure during spinal instrumentation using intraoperative computed tomography-based navigation. Spine J 16:343-354, 2016

20. Mirza SK, Wiggins GC, Kuntz C IV, York JE, Bellabarba C, Knonodi MA, et al: Accuracy of thoracic vertebral body screw placement using standard fluoroscopy, fluoroscopic image guidance, and computed tomographic image guidance: a cadaver study. Spine (Phila Pa 1976) 28:402-413, 2003

21. Neo M, Sakamoto T, Fujibayashi S, Nakamura T: The clinical risk of vertebral artery injury from cervical pedicle screws inserted in degenerative vertebrae. Spine (Phila Pa 1976) 30:2800-2805, 2005

22. Nooh A, Lubov J, Aoude A, Aldebeyan S, Jarzem P, Ouellet J, et al: Differences between manufacturers of computed tomography-based computer-assisted surgery systems do exist: a systematic literature review. Global Spine J 7:83-94, 2017

23. Nottmeier EW, Pirris SM, Edwards S, Kimes S, Bowman C, Nelson KL: Operating room radiation exposure in cone beam computed tomography-based, image-guided spinal surgery: clinical article. J Neurosurg Spine 19:226-231, 2013

24. Nottmeier EW, Seemer W, Young PM: Placement of thoracolumbar pedicle screws using three-dimensional image guidance: experience in a large patient cohort. J Neurosurg Spine 10:33-39, 2009

25. Rajasekaran S, Vidyadhara S, Ramesh P, Shetty AP: Randomized clinical study to compare the accuracy of navigated and non-navigated thoracic pedicle screws in deformity correction surgeries. Spine (Phila Pa 1976) 32:E56-E64, 2007

26. Rivkin MA, Yocom SS: Thoracolumbar instrumentation with CT-guided navigation $(\mathrm{O}$-arm) in 270 consecutive patients: accuracy rates and lessons learned. Neurosurg Focus 36(3):E7, 2014

27. Ruatti S, Dubois C, Chipon E, Kerschbaumer G, Milaire M, Moreau-Gaudry A, et al: Interest of intra-operative 3D imaging in spine surgery: a prospective randomized study. Eur Spine J 25:1738-1744, 2016

28. Sakai Y, Matsuyama Y, Nakamura H, Katayama Y, Imagama S, Ito Z, et al: Segmental pedicle screwing for idiopathic scoliosis using computer-assisted surgery. J Spinal Disord Tech 21:181-186, 2008

29. Shin BJ, James AR, Njoku IU, Härtl R: Pedicle screw navigation: a systematic review and meta-analysis of perforation risk for computer-navigated versus freehand insertion. J Neurosurg Spine 17:113-122, 2012
30. Shin MH, Hur JW, Ryu KS, Park CK: Prospective comparison study between the fluoroscopy-guided and navigation coupled with $\mathrm{O}$-arm-guided pedicle screw placement in the thoracic and lumbosacral spines. J Spinal Disord Tech 28:E347-E351, 2015

31. Silbermann J, Riese F, Allam Y, Reichert T, Koeppert H, Gutberlet M: Computer tomography assessment of pedicle screw placement in lumbar and sacral spine: comparison between free-hand and $\mathrm{O}$-arm based navigation techniques. Eur Spine J 20:875-881, 2011

32. Steudel WI, Nabhan A, Shariat K: Intraoperative CT in spine surgery. Acta Neurochir Suppl 109:169-174, 2011

33. Tormenti MJ, Kostov DB, Gardner PA, Kanter AS, Spiro RM, Okonkwo DO: Intraoperative computed tomography image-guided navigation for posterior thoracolumbar spinal instrumentation in spinal deformity surgery. Neurosurg Focus 28(3):E11, 2010

34. Treier R, Aroua A, Verdun FR, Samara E, Stuessi A, Trueb PR: Patient doses in CT examinations in Switzerland: implementation of national diagnostic reference levels. Radiat Prot Dosimetry 142:244-254, 2010

35. Vaccaro AR, Rizzolo SJ, Balderston RA, Allardyce TJ, Garfin SR, Dolinskas C, et al: Placement of pedicle screws in the thoracic spine. Part II: An anatomical and radiographic assessment. J Bone Joint Surg Am 77:1200-1206, 1995

36. Valentin J (ed): The 2007 Recommendations of the International Commission on Radiological Protection. ICRP Publication 103. Ann ICRP 37:1-332, 2007

37. Waschke A, Walter J, Duenisch P, Reichart R, Kalff R, Ewald $\mathrm{C}$ : CT-navigation versus fluoroscopy-guided placement of pedicle screws at the thoracolumbar spine: single center experience of 4,500 screws. Eur Spine J 22:654-660, 2013

38. Wendl K, von Recum J, Wentzensen A, Grützner PA: [Iso$\mathrm{C}^{3 \mathrm{D}}$-assisted navigated implantation of pedicle screws in thoracic lumbar vertebrae.] Unfallchirurg 106:907-913, 2003 (Ger)

39. Zhang J, Weir V, Fajardo L, Lin J, Hsiung H, Ritenour ER: Dosimetric characterization of a cone-beam O-arm imaging system. J XRay Sci Technol 17:305-317, 2009

\section{Disclosures}

Dr. Del Grande has received speaking honoraria from Siemens and Bayer, and Dr. Scarone is a consultant for DePuy Synthes.

\section{Author Contributions}

Conception and design: Scarone, Reinert. Acquisition of data: Scarone, Vincenzo, Distefano, Presilla. Analysis and interpretation of data: Scarone, Vincenzo, Distefano, Presilla. Drafting the article: Scarone. Critically revising the article: Scarone, Del Grande, Cianfoni, Presilla. Reviewed submitted version of manuscript: Scarone. Approved the final version of the manuscript on behalf of all authors: Scarone. Study supervision: Scarone, Del Grande, Cianfoni, Reinert.

\section{Supplemental Information \\ Previous Presentations}

Portions of this work were presented as proceedings at the 15 th Interim Meeting of the World Federation of Neurosurgical Societies held in Rome, Italy, on September 8, 2015; the Joint Annual Meeting of the Swiss Society of Neurosurgery and Neuroradiology held in Lucerne, Switzerland, on September 10, 2015; and the Global Spine Congress held in Milan, Italy, on May 3, 2017.

\section{Correspondence}

Pietro Scarone: Ospedale Regionale di Lugano, Lugano, Switzerland. pietro.scarone@eoc.ch. 